\title{
Environmental Sustainability Approaches Adopted for Anhsin Bridge Construction of Ankeng Metro System in New Taipei City in Taiwan
}

\author{
Tai-Yi Liu ${ }^{1, *}$, Po-Han Chen ${ }^{2}$, Nelson N.S. $\mathrm{Chou}^{3}$, Mao-Yi Chou ${ }^{4}$, Jui-Jiun Lin ${ }^{5}$, Han-Ting Lo ${ }^{6}$ \\ 1-3 Department of Civil Engineering, National Taiwan University, No. 1, Sec. 4, Roosevelt Rd., Taipei 10617, Taiwan, R.O.C. \\ ${ }^{4-5}$ Department of Rapid Transit Syatems, No. 245, Ji-Xian Rd., New Taipei City 24747, Taiwan, R.O.C. \\ ${ }^{6}$ MAA Group, 22 Fl., No. 112, Sec. 1, Xintai Wu Rd., Xizhi District, New Taipei City 22102, Taiwan, R.O.C.
}

\begin{abstract}
The Ankeng Light Rail Metro System (ALRMS) is a Design-Build (DB) construction project located in New Taipei City. The Anhsin Bridge (AB) is one of the major parts of ALRMS. The original concept from the client, the Department of Rapid Transit Systems (DRTS), New Taipei City Government, was to design Anhsin Bridge as a steel arch bridge, which inevitably would require construction of some piers in the river reservation zone. Also, a temporary access bridge would be necessary during the erection of the steel frame. All these would pose a harmful situation for the river flow. Considering environmental sustainability, the contractor proposed a sustainable construction method, the unbalanced cable-stayed design with truss frames (UBCSTF), to build the Anhsin Bridge. Without constructing piers in the river reservation zone, the pylon of the Anhsin Bridge was laid on a $5.5 \mathrm{~m}$ thickness foundation supported by $42 \mathrm{2m}$-diameter bored piles. A friendly environmental achievement was made by adopting UBCSTF. In this paper, the authors will share the rare construction experiences with the Anhsin Bridge construction, and present the detailed design concept, construction, and environmental sustainability achievements in this project.
\end{abstract}

\section{Introduction}

\subsection{Foreword}

Sustainability indicators for infrastructure were proposed in the past decades [1][2], with the Key Assessment Indicators proposed for evaluating sustainability issues in engineering fields [3]. In recent years, sustainability issues have been widely studied and discussed in all engineering fields as well as construction. The main purpose of conducting sustainability research is to prevent construction projects from depleting resources and/or causing harmful effect and impact on the environment and ecology during their lifecycles [3][4]. In this project, engineers have been focusing on environmental sustainability to minimize potential impact on the environment during the lifecycle of the Ankeng Light Rail Metro System (ALRMS). Fig. 1 shows the research framework in this paper.

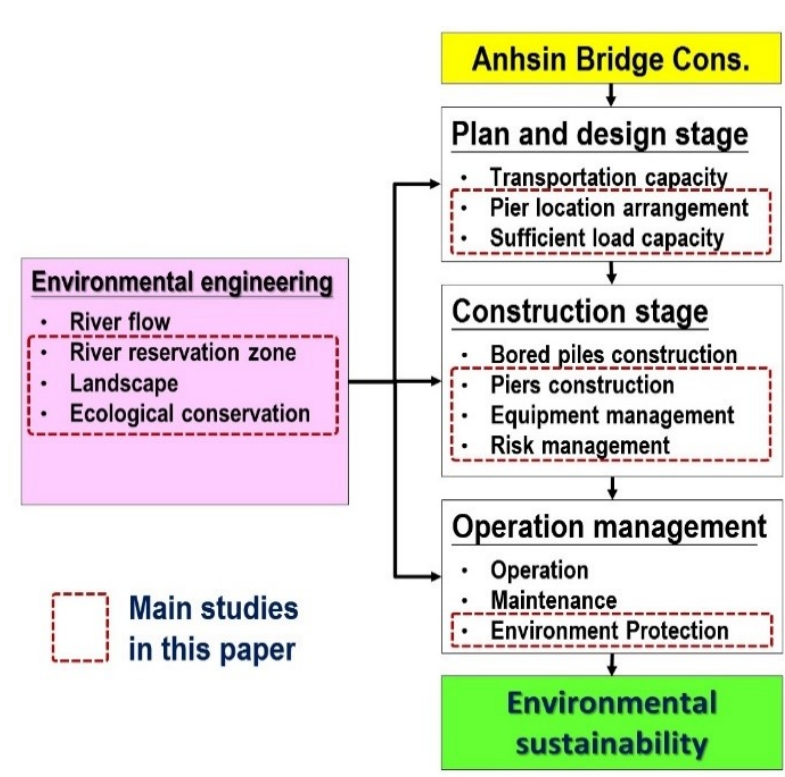

Fig. 1. Research framework

\subsection{Project description}

The Ankeng Light Rail Metro System (ALRMS) is an important public transportation system under construction and is expected to complete in 2021 , including the

* Corresponding author: tylaytpe@ms9.hinet.net 
completion of the depot zone. Fig. 2 shows the route layout of the whole project.

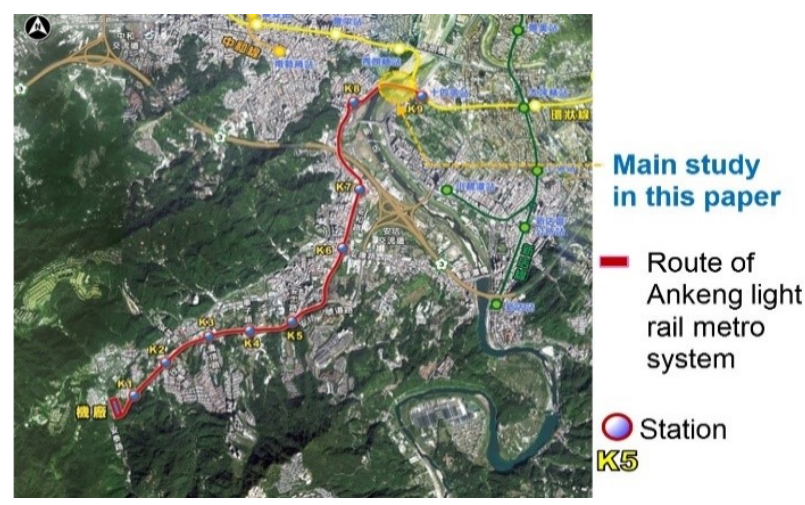

Fig. 2. The route layout of the Ankeng project. (Source: Tai-Yi Liu)

ALRMS has a total length of 7.5 kilometers and nine stations, including five elevated stations and four at-grade stations. The three bridges crossing the No. 3 Freeway, Hsinpei Highway and Hsindian River were designed differently in accordance with the design codes.

In addition to design codes, environmental and ecological sustainability was considered in conceptual design. In this paper, the environmental sustainability approaches adopted for Anhsin Bridge (AB) construction will be presented.

\section{Challenges and Solutions}

\subsection{Environmental sustainability}

The route between $\mathrm{K} 8$ and $\mathrm{K} 9$ stations passes the Hsindian River and building a bridge is easier than building an underground tunnel. The original design proposed by the client DRTS was a steel arch bridge, as shown in Fig. 3.

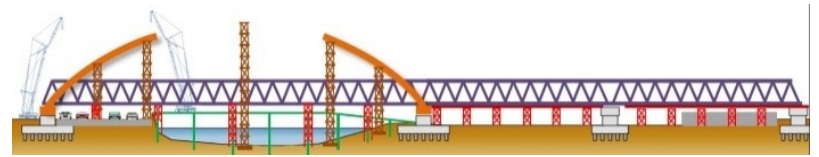

Fig. 3. The original design concept of Anhsin Bridge.

As shown in Fig. 3, it was unlikely to avoid construction of piers and setup of temporary access bridges, scaffoldings, and other temporary supporting structures in the river reservation zone. With this design, the influence on the river flow would not only occur in the construction stage, but also in the operation stage. Considering environmental sustainability, other bridge designs that are more environmentally friendly should be proposed for this project.

The Ankeng Light Rail Metro System (ALRMS) project is a Design-Build (DB) project, and the contractor, New Asia Construction and Development Corporation, is one of the largest construction companies in Taiwan. With the responsibility for environmental protection in mind, the contractor decided to build the Anhsin Bridge $(\mathrm{AB})$ using the unbalanced cable-stayed design with truss frames (UBCSTF) method, even if it might be more costly than the original steel arch bridge design. Fig. 4 shows the draft sketch and simulation image of the new AB. The UBCSTF design greatly reduced the impact on the environmental and exemplified how engineers could help achieve a sustainable environment.

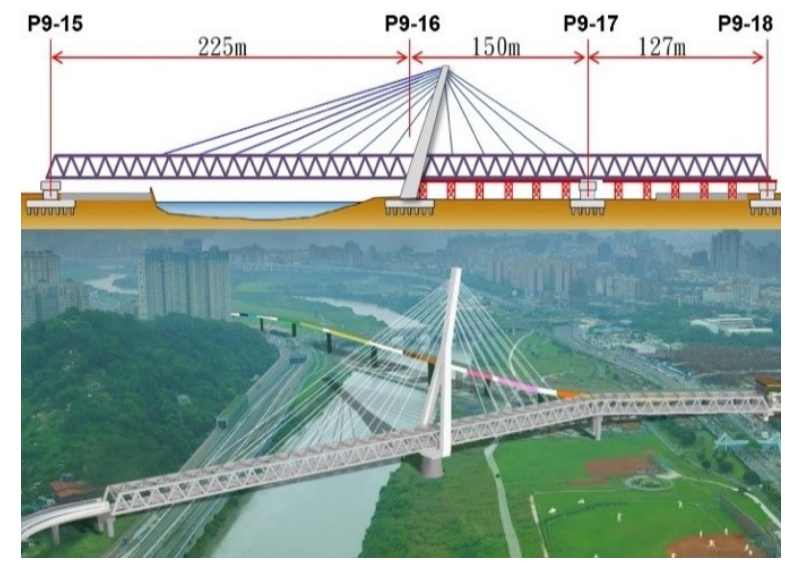

Fig. 4. The draft sketch and simulation image of new Anhsin Bridge. (Source: Tai-Yi Liu)

\subsection{Huge load on pier foundation}

The total length of $\mathrm{AB}$ is $502 \mathrm{~m}$. A total of four piers, P915, P9-16, P9-17, and $\mathrm{P} 9-18$ are designed as the substructure of the bridge. $\mathrm{AB}$ includes three major parts, including a $130 \mathrm{~m}$ height pylon, a $502 \mathrm{~m}$ truss frame, and 24 (12 pairs) steel cables. The live and dead loads of the $375 \mathrm{~m}$ truss frame are transferred to the pylon of the P9-16 pier by the 24 steel cables. Thus, most of the bridge loads are taken by the P9-16 pier, and a huge load capacity is required for the $\mathrm{P} 9-16$ pier.

A total of 42 2m-diameter, $35 \mathrm{~m}$-deep bored piles were designed to bear the huge load transferred from the $5.5 \mathrm{~m}$ thickness pile cap. Fig. 5 shows the construction of the piles and Fig. 6 shows the inspection of foundation.

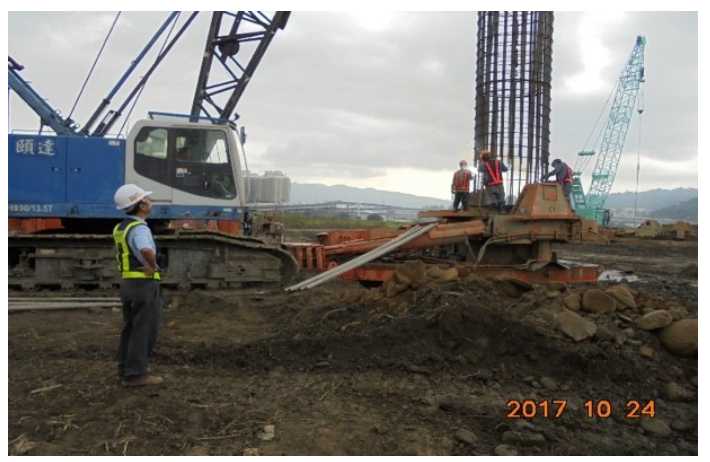

Fig. 5. The construction of the $2 \mathrm{~m}$-diameter piles supervised by the first author. 


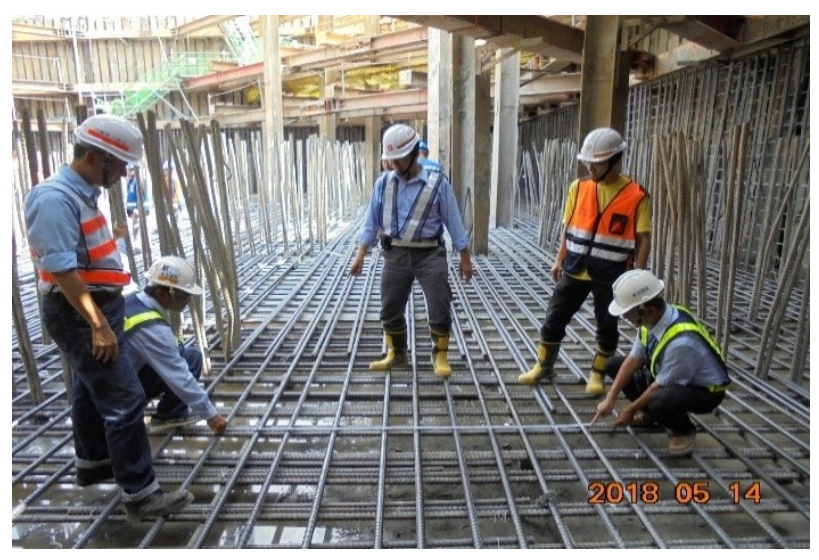

Fig. 6. The inspection of foundation by the authors.

To verify the actual performance of the piles, a pile static loading test was conducted in the field, and a wellplanned test procedure [5] was carried out. Table 1 shows the basic data for the pile test.

Table 1. Basic data for the pile test.

\begin{tabular}{|l|c|}
\hline \multicolumn{1}{|c|}{ items } & Values \\
\hline $\begin{array}{l}\text { Design vertical load-normal } \\
\text { condition (t) }\end{array}$ & 974 \\
\hline $\begin{array}{l}\text { Design vertical load-earth } \\
\text { quake condition ( })\end{array}$ & 2,287 \\
\hline Design pile length (m) & 35.0 \\
\hline Diameter of test pile (cm) & 200 \\
\hline Extended portion length (m) & 12.5 \\
\hline $\begin{array}{l}\text { Friction of extended portion } \\
\text { (t) }\end{array}$ & 593.96 \\
\hline Maximum test load & $2,881 \mathrm{t}$ \\
\hline $\begin{array}{l}\text { Total pile length (m, includes } \\
\text { extended portion) }\end{array}$ & $35.0+12.5=47.5$ \\
\hline Anchor force type & Anchor piles \\
\hline Anchor force supply & Diameter $=2.0 \mathrm{~m}, \mathrm{~L}=47.2 \mathrm{~m}$ \\
\hline Connection rebars & SD420W\#11-24 $\times 2=48$ Pics. \\
\hline Rebar welding & Fillet weld, L=16cm \\
\hline
\end{tabular}

The maximum test load is calculated using Eq. (1).

Max. $\{(2 *$ Normal vertical load $)$, Earthquake vertical load $\}+$ Friction of extended portion

where the maximum test load was $(2,287+593.96)=$ $2,880.96$, namely 2,881 tons.

The bearing capacity of the test pile and the friction of anchor pile were calculated using Eqs. (2) and (3), respectively.

$$
\begin{gathered}
Q u=q_{b} A b+\Sigma f_{s} A_{s} \\
Q s=(N s / 3) * 2 \pi * A s
\end{gathered}
$$

The testing was carried out with some major components, including hydrulic jacks, anchor beams, reference beams and monitoring instruments. Fig. 7 shows the testing scene.

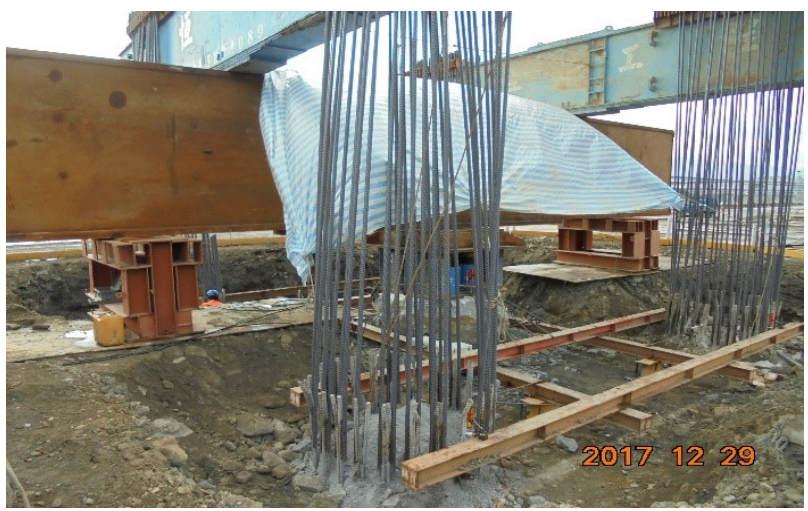

Fig. 7. The testing scene.

According to the test procedure [5], vertical loads should be gradually applied using the hydraulic jacks. Table 2 shows the pile test steps and the load applied in each step.

Table 2. The pile test steps and the load applied in each

\begin{tabular}{|c|c|c|c|c|c|c|c|c|c|}
\hline $\begin{array}{l}\text { Loading } \\
\text { Steps }\end{array}$ & $\mathbf{0}$ & 1 & 2 & 3 & 4 & 5 & 6 & 7 & 8 \\
\hline $\begin{array}{c}\text { Load } \\
\text { percentage } \\
(\%)\end{array}$ & 0 & 12.5 & 25.0 & 37.5 & 50.0 & 62.5 & 75.0 & 87.5 & 100 \\
\hline Load & 0 & 358 & 716 & 1074 & 1433 & 1791 & 2149 & 2507 & 2881 \\
\hline $1^{\text {st }}$ hour & & $\bigcirc$ & & & & & & & \\
\hline $2^{\text {nd }}$ hour & & & $\bigcirc$ & & & & & & \\
\hline $3^{\text {rd }}$ hour & & & & 0 & & & & & \\
\hline $4^{\text {th }}$ hour & & & & & 0 & & & & \\
\hline $5^{\text {th }}$ hour & & & & & & $\bigcirc$ & & & \\
\hline $6^{\text {th }}$ hour & & & & & & & $\bigcirc$ & & \\
\hline $7^{\text {th }}$ hour & & & & & & & & 0 & \\
\hline $8^{\text {th }}$ hour & & & & & & & & & $\bigcirc$ \\
\hline $20^{\text {th }}$ hour & & & & & & & 0 & & \\
\hline $21^{\text {st }}$ hour & & & & & 0 & & & & \\
\hline $22^{\text {nd }}$ hour & & & O & & & & & & \\
\hline $34^{\text {th }}$ hour & $\Delta$ & & & & & & & & \\
\hline $\begin{array}{c}\text { Release } \\
\text { steps }\end{array}$ & 12 & & 11 & & 10 & & 9 & & 8 \\
\hline
\end{tabular}
step.

After eight hours of static loading test, the maximum load and the corresponding pile top settlement were 2,881 tons and $16.67 \mathrm{~mm}$, respectively. The load was gradually released down to zero after keeping of maximum load for 12 hours. The net settlement was $3.52 \mathrm{~mm}$, measured after full release of loads. The maximum settlement and net settlement verified that the actual pile capacity met the design requirement with a safe factor of 3 . Fig. 8 shows the load-settlement diagram of the pile static loading test. 


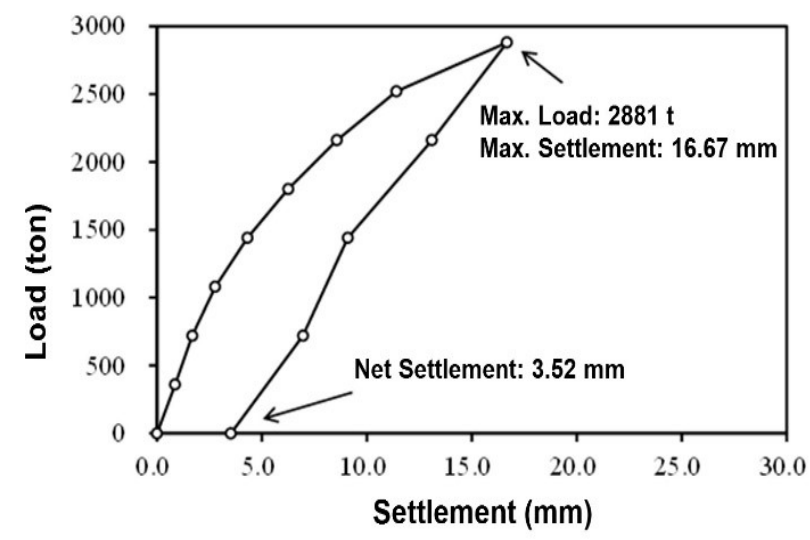

Fig. 8. The load-settlement diagram of the pile static loading test.

\subsection{Steel truss frame erection}

To avoid the river flow from being affected by the temporary shoring system during the erection of the steel truss frame, the contractor proposed to use the erection system for truss frame (ESTF) for the erection work. The ESTF included three major pieces of heavy-duty equipment, a lifting crane, a mobile trolley and an erection crane. They were specially designed for the construction of steel truss frame of AB.

With ESTF, no temporary equipment or structure was needed in the river reservation zone during the construction of the steel truss frame. Figs. 9 and 10 show the design drawing and site photo of ESTF, respectively. Fig. 11 shows the bolt tightening of steel truss frame under the first author's supervision.

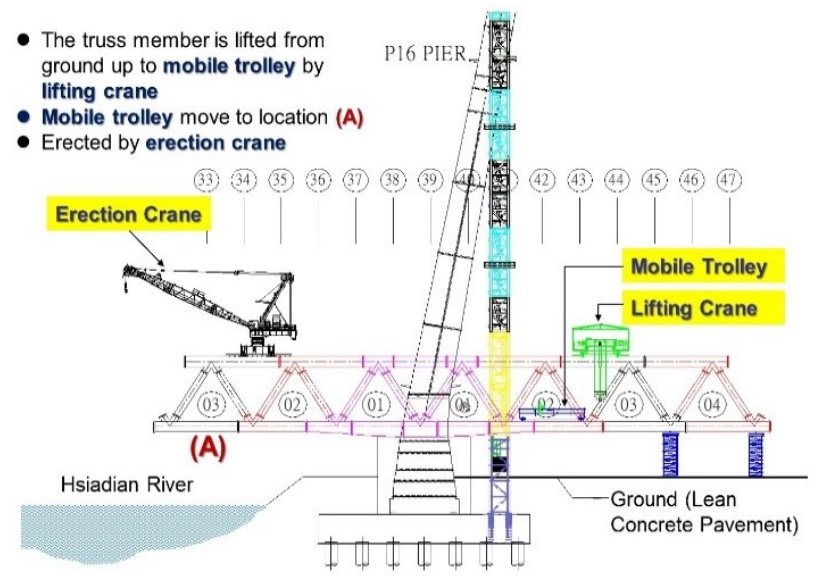

Fig. 9. The design drawing of the erection system for truss frame (ESTF).

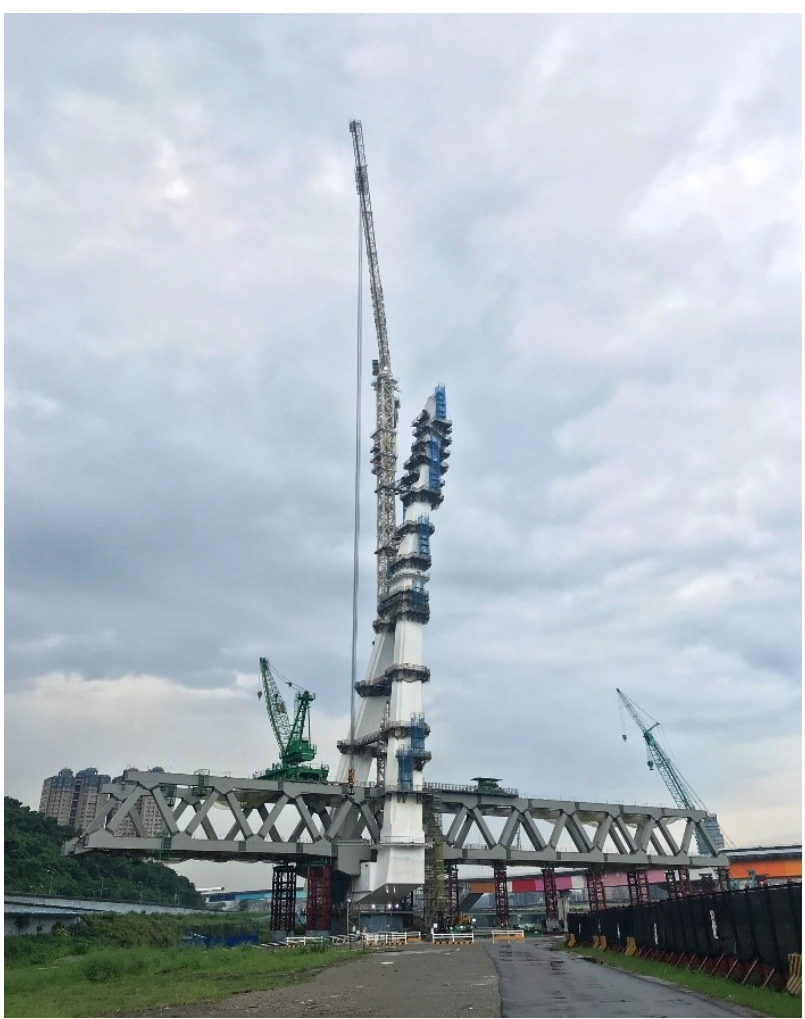

Fig.10. The site photo of the erection system for truss frame (ESTF).

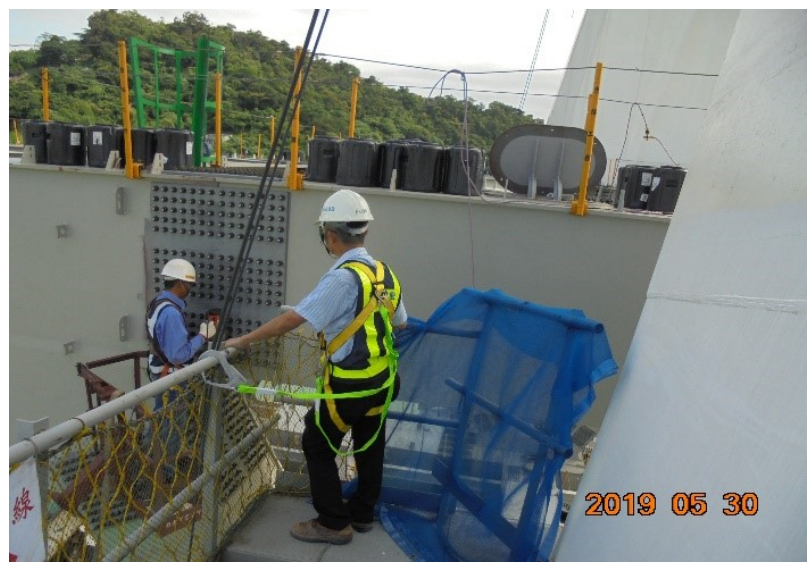

Fig. 11. The bolt tightening of steel truss frame under the first author's supervision.

\subsection{Wind force}

Prior to the connection of the steel truss frame and Pier P9-15, the bridge body was not stable due to the cantilever condition. The horizontal force caused by wind, such as that from typhoons, might seriously damage the structure of steel truss frame. For realization of the lateral displacement of steel truss frame under cantilever condition, wind tunnel tests [6] were conducted.

The bridge members were produced by $3-\mathrm{D}$ printing in a $1 / 100$ scale. A series of tests in different wind directions, inclusive of $30^{\circ}, 45^{\circ}, 60^{\circ}, 90^{\circ}, 120^{\circ}, 135^{\circ}$ and $150^{\circ}$, were conducted. The maximum lateral displacement under the most critical condition was measured as $830 \mathrm{~mm}$ with a wind speed of $74 \mathrm{~m} / \mathrm{second}$. The maximum wind force was calculated using Eq. (4). 


$$
P=0.124 * V^{2}
$$

Through careful analysis of the steel truss frame with a lateral displacement of $830 \mathrm{~mm}$, the bridge structure was confirmed to be safe with a reliable safety factor. Fig. 12 shows the wind tunnel test in the laboratory.

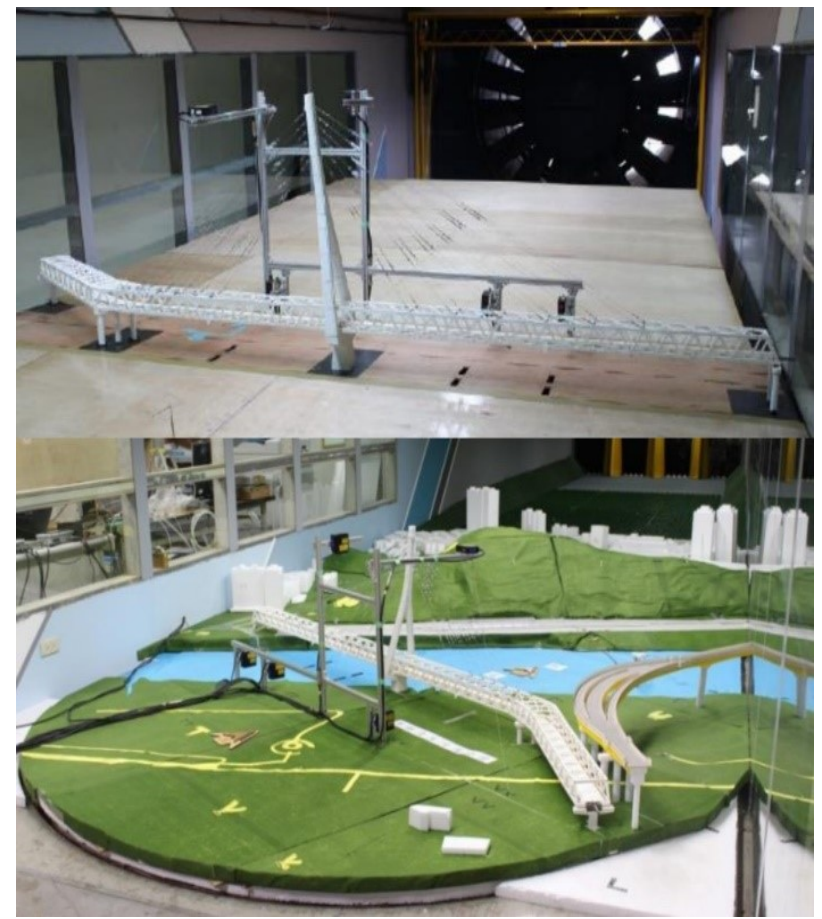

Fig. 12. The wind tunnel test in the laboratory.

\subsection{Management of massive member sizes}

There were more than fifty thousand steel members of various shapes and sizes specified in the drawing. A reliable management system for raw materials and their manufacturing, assembly, transportation and erection should be established in order to carry out construction work without any mistakes. Fig. 13 shows the traceability of material management.

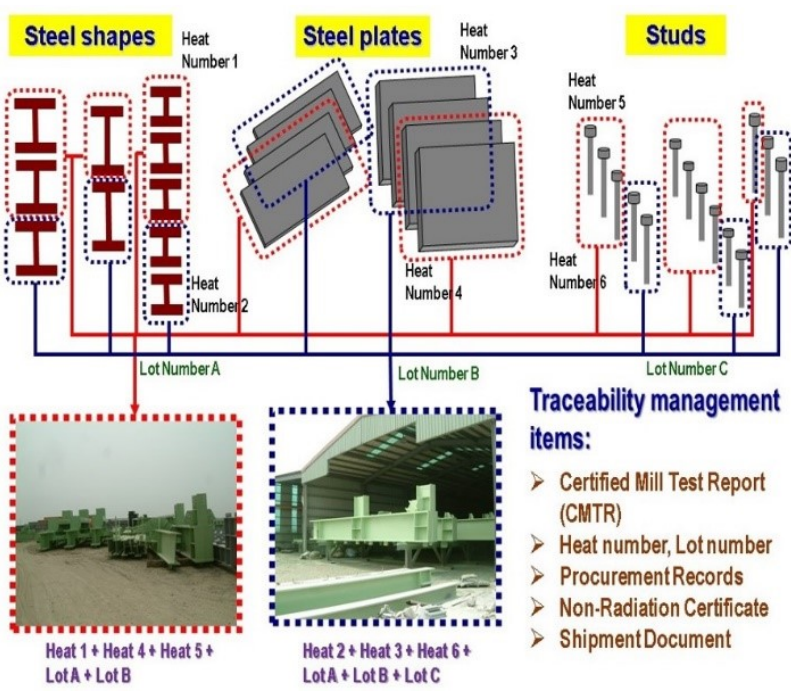

Fig. 13. The traceability of material management.
Adopting building information modeling (BIM) [7] helped engineers with excellent management for Anhsin Bridge $(\mathrm{AB})$ construction. Each single piece could be modeled in 3-D using BIM with traceable ID number, shape, size, installation location, etc. BIM not only enabled engineers to manage construction work in an efficient and effective way, but also detected potential clashes between different members and resolved them prior to installation and/or erection. Fig. 14 shows BIM output for the $\mathrm{AB}$ steel truss frame.
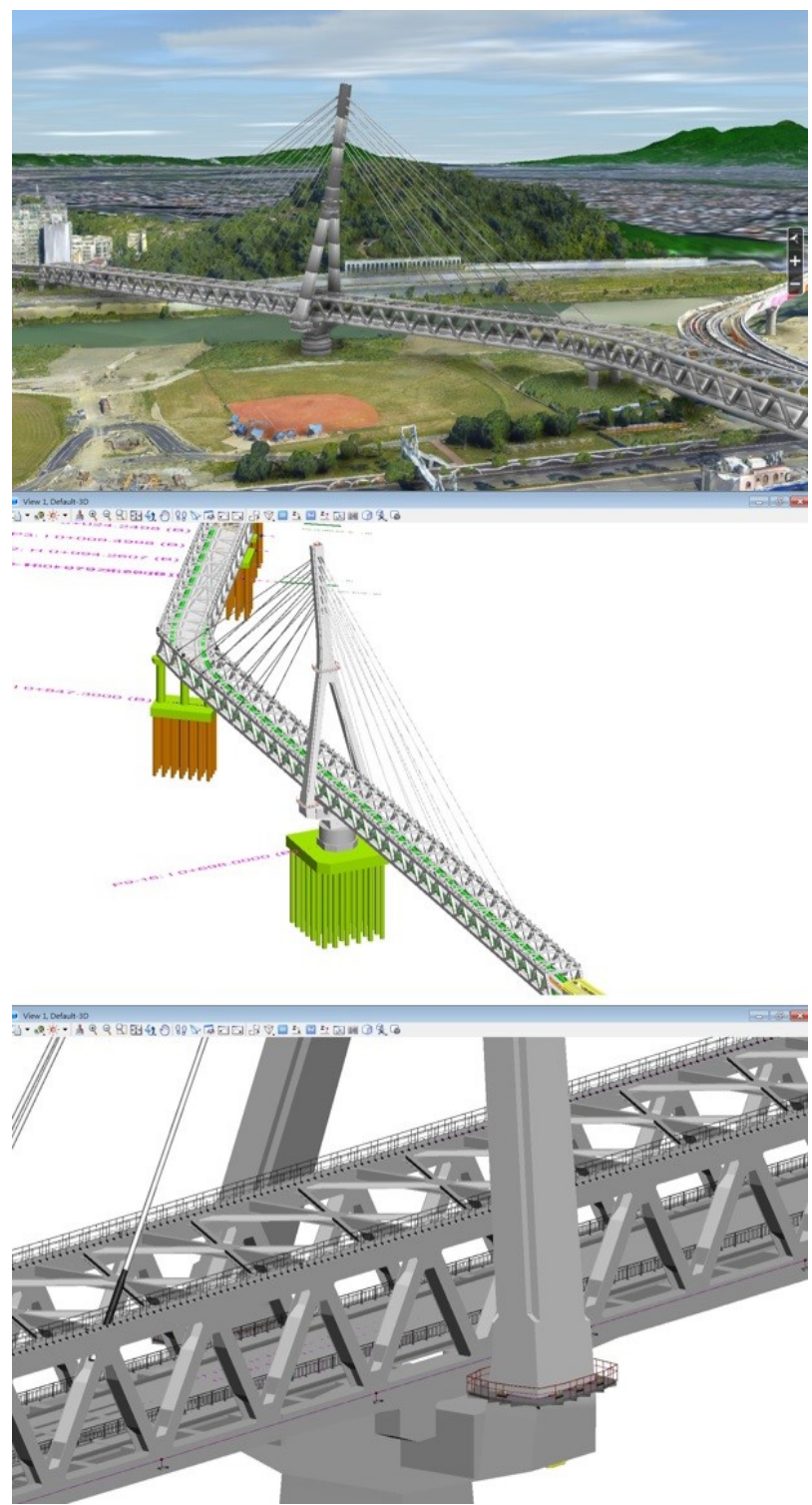

Fig. 14. BIM output for the steel truss frame of the Anhsin Bridge.

\section{Environmental Sustainability Achievement}

\subsection{Key sustainability indicators for green civil infrastructure}

The authors established a set of key sustainability indicators for green civil infrastructure, including safety, 
ecology, environmental protection and carbon emissions reduction, energy saving, waste reduction, durability, benefit, landscape, humanities and culture reservation, and creativity [3]. Three evaluation levels with weights are contained in this system. Table 3 shows the major evaluation items (Level 2) contained in each indicator (Level 1) that are discussed in this project. The evaluation items that are well-considered and discussed in this project are marked in yellow. Fig. 15 shows the three levels of the green civil infrastructure assessment system [3].

Table 3. The major evaluation items contained in each indicator those are discussed in this project [3].

\begin{tabular}{|c|c|}
\hline Indicator & Evaluation items \\
\hline \multirow{5}{*}{ Ecology } & $\begin{array}{l}\text { Ecological environment investigation, data } \\
\text { collection and impact assessment }\end{array}$ \\
\hline & $\begin{array}{l}\text { Original spot's preservation and indicative } \\
\text { trees protection }\end{array}$ \\
\hline & Ecological environment monitoring \\
\hline & $\begin{array}{l}\text { Selection of low impact construction methods } \\
\text { and preservation of biodiversity and animal } \\
\text { habitat integrity }\end{array}$ \\
\hline & Establishment of safety facilities for animals \\
\hline \multirow{8}{*}{$\begin{array}{l}\text { Environmental } \\
\text { protection and } \\
\text { carbon } \\
\text { emissions } \\
\text { reduction }\end{array}$} & Environmental impact assessment \\
\hline & Monitoring of carbon emission in the lifecycle \\
\hline & Selection of low carbon emission materials \\
\hline & $\begin{array}{l}\text { Establishment of carbon emission reduction } \\
\text { mechanism and selection of the construction } \\
\text { methods with low-carbon emissions }\end{array}$ \\
\hline & $\begin{array}{l}\text { Construction methods and procedures with } \\
\text { low pollution (airborne particles, waste water, } \\
\text { wastes, etc.) }\end{array}$ \\
\hline & Lifecycle soil and water conservation plan \\
\hline & $\begin{array}{l}\text { Planting of tress with high carbon-absorption } \\
\text { abilities }\end{array}$ \\
\hline & $\begin{array}{l}\text { Underground reservoir design with long-term } \\
\text { maintenance for the facility }\end{array}$ \\
\hline \multirow{6}{*}{ Durability } & Durable structure design \\
\hline & Use of durable materials \\
\hline & Adaptive/upgradable design \\
\hline & $\begin{array}{l}\text { Adoption of long earthquake and flood } \\
\text { regression periods for design }\end{array}$ \\
\hline & $\begin{array}{l}\text { Establishment of excellent } \\
\text { operation/maintenance mechanism }\end{array}$ \\
\hline & Cost down in the lifecycle \\
\hline \multirow{7}{*}{$\begin{array}{l}\text { Landscape, } \\
\text { humanities and } \\
\text { culture } \\
\text { reservation }\end{array}$} & $\begin{array}{l}\text { Take local culture into consideration in } \\
\text { structure design }\end{array}$ \\
\hline & Design of structure for landscape fusion \\
\hline & $\begin{array}{l}\text { Beautification of design of structure and } \\
\text { landscaping }\end{array}$ \\
\hline & $\begin{array}{l}\text { Provision of participation and communication } \\
\text { to the public }\end{array}$ \\
\hline & Care for minorities \\
\hline & Protection of historical sites and cultural relics \\
\hline & Creation of public art \\
\hline \multirow{3}{*}{ Creativity } & $\begin{array}{l}\text { Introduction of new materials, new } \\
\text { construction methods, new technologies, etc. }\end{array}$ \\
\hline & Innovation in engineering project design \\
\hline & $\begin{array}{l}\text { Combination of project with scenery and } \\
\text { culture }\end{array}$ \\
\hline
\end{tabular}

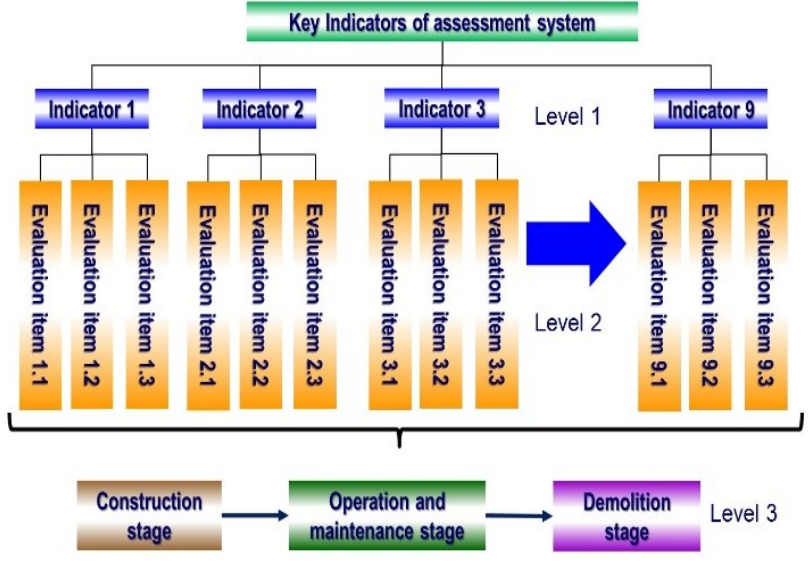

Fig. 15. Three levels of the green civil infrastructure assessment system [3].

\subsection{Environmental sustainability achievement by Anhsin Bridge}

In this paper, the authors highlighted some major sustainability practices of the Anhsin Bridge (AB) as follows:

- Environmental sustainability: Through adopting UBCSTF and cancelling of piers and other construction facilities that might be located and constructed in the river reservation zone, potential impacts on Hsindian River were avoided. Also, impact on river flow and species in the river was minimized in the construction and operation stages.

- Efficiency of equipment and machines for carbon reduction [8]: Carbon emission was reduced through optimizing equipment and machine management. This achievement was realized especially due to good planning of BSTF.

- Research on specified species [9]: Since construction could severely impact the habitats of local species, biologists were engaged in the $\mathrm{AB}$ project and they implemented a research program for Hsindian River and its tributaries to monitor any changes in species' population and health during construction. Fig. 16 shows some species that were monitored, observed and analyzed.

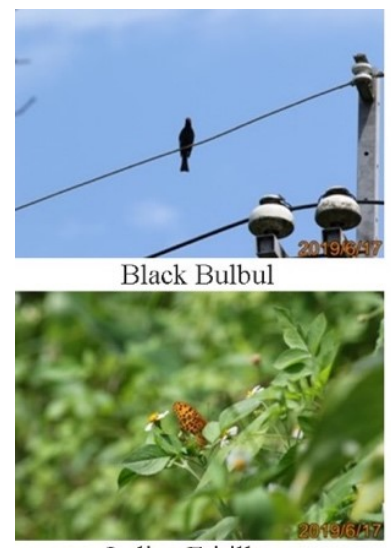

Indian Fritillary

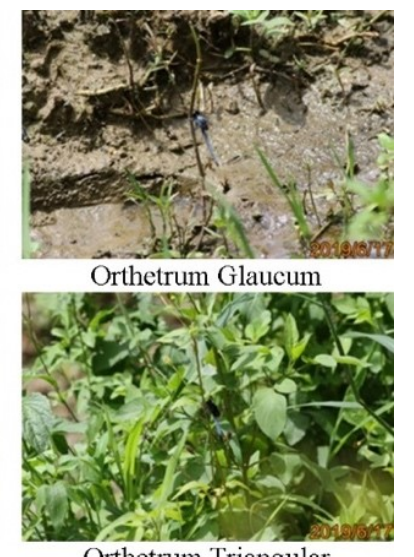

Orthetrum Triangular
Fig. 16. Some species that were monitored, observed and analyzed. 


\section{Conclusion}

The contractor proposed the unbalanced cable-stayed design with truss frame (UBCSTF) method for the Anhsin Bridge construction to meet the goal of environmental sustainability, ecology protection, landscape, and carbon emission reduction. Moreover, the efficiency of materials management was optimized through the use of building information modeling (BIM). The presented successful practices adopted in this project for environmental sustainability during construction could serve as a good reference for similar bridge projects in the future.

\section{Acknowledgement}

Special thanks are given to the Department of Rapid Transit Systems-Ankeng Light Rail Metro System Office, the office director, and all the engineers in the office for their instructions and supervision in the course of construction. Their efforts speak for the success in achieving environmental sustainability in the project. Also, great thanks are given to Sinotech Engineering Consultants, Ltd. and the MAA group for their help and studies in the Ankeng Light Rail Metro System Project. We would also like to thank New Asia construction and development Corp. for the friendly environmental engineering and excellent site construction management.

\section{References}

1. World Bank. World development rep. 1994: Infrastructure for development, Oxford University Press, Oxford, UK, 1-12. (1994).

2. World Bank. "Infrastructure at the crossroads: Lessons from 20 years of World Bank experience." Washington, DC, 1-9, 65-80. (2006).

3. T.Y. Liu, P.H. Chen, Nelson N.S. Chou "Comparison of Assessment Systems for Green Building and Green Civil Infrastructure.” Sustainability 2019, 11, 2117. (2019).

4. Shen, Liyin, M.ASCE, Wu, Yuzhe, and Zhang, Xiaoling, (2011). "Key Assessment Indicators for the Sustainability of Infrastructure Projects." J. Constr. Eng. Manage., ASCE 137(6): 441-451.

5. New Asia Construction and Development Corp., "Piles static loading test for the Ankeng Light Rail Metro System construction project.”, Taiwan, R.O.C., (2017, in Chinese)

6. New Asia Construction and Development Corp., "Wind tunnel test plan for the Ankeng Light Rail Metro System construction project.", Taiwan, R.O.C., (2017, in Chinese)

7. New Asia Construction and Development Corp., "Establishment of BIM model for the Ankeng Light Rail Metro System construction project.", Taiwan, R.O.C., (2016, in Chinese)

8. New Asia Construction and Development Corp., "Equipment management plan for the Ankeng Light Rail Metro System construction project.", Taiwan, R.O.C., (2016, in Chinese)
9. New Asia Construction and Development Corp., "Ecology research annual report for the Ankeng Light Rail Metro System construction project.", Taiwan, R.O.C., (2016-2019, in Chinese) 